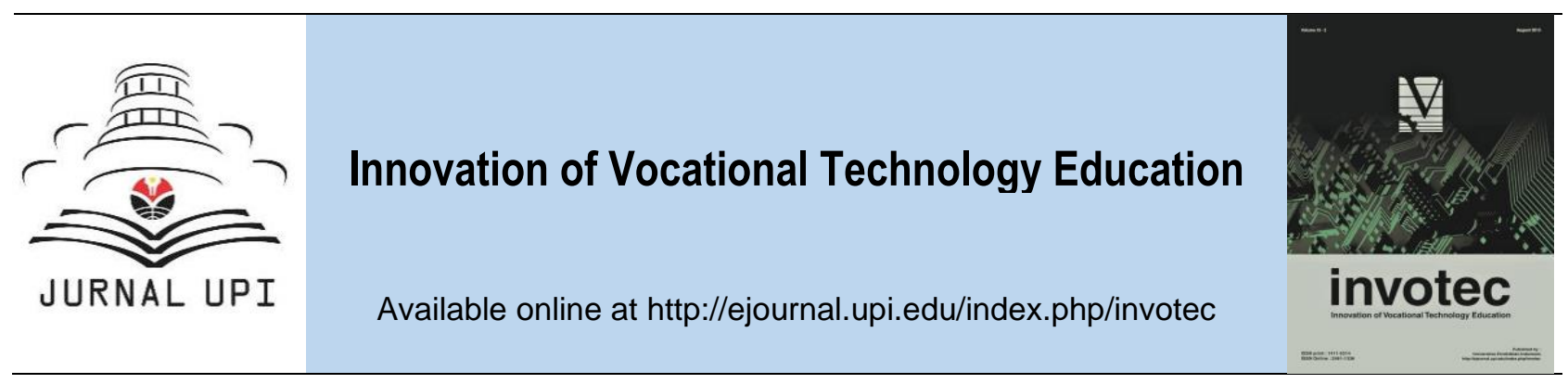

\title{
Design and Development of a Single Page and Web-Based Responsive E-Learning System for Higher Education Institutions
}

\author{
Muhammad Lookman Hossain Khan ${ }^{1,2}$, Agus Setiawan ${ }^{1}$, and Iwan Kustiawan ${ }^{1}$ \\ ${ }^{1}$ Universitas Pendidikan Indonesia, Bandung, Indonesia \\ 2 University of Information Technology and Sciences, Dhaka 1212, Bangladesh
}

\section{ARTICLE INFO}

Article history:

Received: 13 June 2019

Received in revised form: 04 July 2019

Accepted: 25 August 2019

Available online: 31 August 2019

Keywords:

OpenCourseWare;

information system;

E-learning;

higher education

\section{Authors email:}

Ihkhan.dhaka@gmail.com

agus_setiawan@upi.edu

iwan_kustiawan@upi.edu
A B S T R A C T

\begin{abstract}
Students now use not only computers or laptops, but also small devices such as mobile phones. The students at higher education institutions spent a lot of time on the internet to find the course materials. Sometimes the teacher sends the materials, but the students who are willing to take a specific course of a semester cannot get a brief concept of the course on before starting the semester. There is now a lot of online education systems on the Internet, but few are a single page and responsive. The purpose of this research is to develop a single page, responsive and web-based e-learning system. The method used in this research is the Rapid Application Development approach which has six stages of the development process, namely Planning, Analysis, Design, Implementation, Testing, and Maintenance. This research was conducted in the Faculty of Technology and Vocational Education, Universitas Pendidikan Indonesia. The students and teachers from the Department of Mechanical Engineering Education participated in this research. The results of this research indicate that with fully functional live chat, the OpenCourseWare system has a high usability test score, highly responsive and awesome features. The OpenCourseWare system is responsive and ajax-based mobile-friendly system that can be used by higher education institutions as an e-learning system based on the results obtained.
\end{abstract}

\section{Introduction}

E-Learning is a system that represents the Open Courseware system to maintain the course materials and videos at Universitas Pendidikan Indonesia which is located in Bandung City. The students from Universitas Pendidikan Indonesia spent a lot of time on the Internet to find the course materials or sometimes teacher sends the materials, but the students who are willing to take a specific course of a semester cannot get a brief concept of the course on before starting the semester. Teachers need to provide lecture materials after a class, but sometimes they forget to send them and sometimes teachers are also busy so they send the files to students later on using 
e-mail or Whatsapp. But most of the time files are sent by using a flash disk. Teachers usually do not allow students to use a flash disk because of the spread of malware by flash disk. In this modern era, students need to access course materials anytime, anywhere in order to access in the age of lifelong learning. Finding a course material on the Internet nowadays is easy, but access to the materials is quite tough because of not open access to the materials. Most of the time they need registration for downloading files, but after they registrar, they come to know that they have to pay for the materials.

There are now a lot of online education systems on the Internet, but few are Single Page and Responsive. Nowadays students not only use computers or laptops but they also use small devices e.g. mobile phones (Straker et al., 2018). When students visit those sites from mobile phones, they cannot see the big page through a mobile screen. The traditional web application on e-learning does not give the students a good browsing experience because the traditional system uses basic HTML design (Jadhav, Sawant, \& Deshmukh, 2015). The primary aim of this system is to provide students with a better and more efficient way to obtain course materials and information along with other utility features. A single page and responsive web-based courseware system will be developed in this project for the Universitas Pendidikan Indonesia where students will be allowed to access course materials uploaded by the teachers of the university so that students will find all in one. The primary purpose of this system is to permit students and teachers to easily access the coursework anytime and anywhere and communication with each other while using the system.

\section{Literature Review}

\section{$2.1 \quad$ E-learning}

Since the late 1990s, there has been a huge premium appeared in e-learning by professionals and scholastics alike. E-learning was initially employed as an emotionally supportive network for separation learning and this is the reason e-learning is regularly called separate training, despite the fact that e-learning is a smaller idea. E-learning, which depends on remote correspondence between an instructor and an understudy by methods for data advances, is one sort of separation training.

UNESCO specialists characterize e-adapting just and plainly as "learning through the Internet and media" (Yanuschik, Pakhomova, \& Batbold, 2015). E-learning is also utilized to convey preparing, training, and cooperation utilizing different electronic media in any case, overwhelmingly, the Internet, whose apparatuses have comprised the principle driver of e-learning (Siapera, 2017). On the off chance that all around structured and oversaw, e-learning can defeat numerous hindrances related with customary learning. These hindrances incorporate understudies' lateness, plan clashes, inaccessible courses, land disengagement, and statistic and financial disservice (Jones \& Brown, 2007).

The meaning of e-learning is the 'e' in e-learning means 'electronic' and, similar to e-business and comparative cognates that infer PC interceded exercises, e-learning alludes to learning with the 
utilization of ICT. These accords with the definition of the Higher Education Funding Council for England (2005), according to which e-learning refers to 'any learning that uses ICT' (p. 5). In spite of the fact that this definition is sufficiently wide to cover non-online media, similar to reduced circles, the Internet has so ruled the real usage of e-learning simply define e-learning as 'Internet-enabled learning' (Zaheer et al., 2019).

There are few models of e-learning one of them is the open model which is that teaching materials are freely available and any student can use them for self-study. Students here do not have to demonstrate the knowledge gained through a summative evaluation. In open universities, such a model is used (e.g. Virtual University of Pakistan). In the event that we take the expansive feeling of e-learning, which is the utilization of ICT to help understudies in accomplishing their learning results, a blended methodology that consolidates the conventional way to deal with learning is obliged (Biggs, 2011).

\subsection{OpenCourseWare}

OpenCourseWare was originally established in 1999 at the Massachusetts Institute of Technology (MIT) and is an instructive activity to make the centre training materials accessible to Internet customers worldwide for all courses offered by the college at no cost (Carson, 2009; Sun, Wu, \& Lee, 2017). It was initially presented as a model for knowledge sharing at a conference on education technology (Tapia-Leon et al., 2018). It has been contrasted with the development of open source programming since course materials on the OpenCourseWare site are open and unreservedly accessible worldwide for non- business purposes, for example, research and training, giving an exceptional asset for nothing out of the pocket that others can adapt to their own requirements (Hylén, 2006).

OpenCourseWare's objective was to preserve and disseminate valuable educational resources on the Internet (Burbules, 2018). When MIT officially implemented OCW in 2001, many institutions and organizations of higher education quickly developed open educational resources, created and introduced various OCW courses (Soma, Termeer, \& Opdam, 2016). This led to the formation of the OCW Consortium, which facilitated the collection of OCW courses from all over the world. Because of OCW's cooperative approach, each country must invest only a small amount of its resources. The reintegration of educational resources, including the promotion of higher education and the contribution to the global sharing of knowledge, has produced substantial results.

Students can use the Internet for free access to high- quality courses and learning materials. Educators, students, and self- learners confirmed the educational value and positive impact of OCW on self- regulated learning (Hakami, 2018). 


\subsection{Web Application}

A Web Application is fundamentally a client side and server side programming application that keeps running on a Web Server which plays out an explicit capacity by the customer ask for in an Internet browser dissimilar to conventional work area applications (Paulson, 2005). The application can be as simple as a message board or a website contact form or as complex as a word processor or a mobile multiplayer gaming app we download to our phone (Turkle, 2017). People can access a web-based application via a network connection using HTTP instead of existing in the device's memory (Brisebois et al., 2017).

Web applications usually use a server-side script and client-side script combination to develop the application. The client-side script handles the information presentation while the server-side script handles all the hard things such as storing and retrieving the information (McCanne et al., 2016). Common web applications include webmail, online retail sales, online auctions, wikis, instant messaging and much more. Web-based applications are also referred to as web applications.

\subsection{Single Page Application}

A Single Page Application is an application that works inside a browser program and does not require page reloading amid use (Souders, 2008). We are utilizing this sort of uses each day. These are, for example, Gmail, Google Maps, Facebook or GitHub. Single Page Application is all about serving an outstanding UX by trying to imitate a "natural" environment in the browser-no page reloads, no extra wait time. It is only one site page that you visit which at that point stacks all other substance utilizing JavaScript-which they vigorously rely upon. Load faster in single- page application pages when a user navigates the application, which results in a "snapper" user experience after the initial load (Soma, Termeer, \& Opdam, 2016).

\subsection{Responsive web design}

Responsive web design is the approach to design and development based on the screen size, platform and user orientation (Hussain \& Mkpojiogu, 2015). A responsive website uses an alternative set of CSS files depending on the device to which the site is accessed. The website looks and' answers' differently from the device (Frain, 2015).

There was a time when people were only using a desktop computer to access websites. The vast majority had a monitor of the same size. Websites for the average visitor were developed (Kumar \& Jenamani, 2017). Today, people have access to websites from a variety of devices with screens ranging from a few inches to 27 " or higher and expectations have changed. Consumers expect their website to know that they are using a tablet versus a computer. They expect the site to adjust- not the other way around. Different devices have also different usability requirements.

A responsive site takes all this into consideration and automatically adjusts it to provide visitors with the best possible user experience regardless of the device used to access the site (Rosenzweig, 2015). 


\section{Method}

This study was designed to develop a web-based e-learning information system for a university as a source of learning materials for Higher Education via electronic devices. This study is designed to produce a web application which will be used by a university to publish their course materials. The stages of this research are designing and making an information system that manages the planning, implementation and evaluation processes. This research uses Rapid Application Development model. Rapid application development is a form of Agile software development methodology (Abrahamsson et al., 2017). There are six stages in the Rapid application development model which are requirement planning, analysis, design, implementation testing integration, and maintenance or release the product (Martin \& Finkelstein, 1989).

Based on the above scheme, it is explained that the development of the e-learning OpenCourseWare system is done in six stages: A perfect plan for developing OpenCourseWare for Universitas Pendidikan Indonesia develop in this step, calculating the strengths and weaknesses of OpenCourseWare (Berchet \& Habchi, 2005). This step aims to analyze the performance of the software at different stages and to make notes on additional needs (Grant, 2016). The analysis is very important for the next step. Once the analysis has been finished, the design step, which essentially builds the project architecture, is taken over. This step helps to eliminate possible defects by setting a standard and trying to abide by it. The actual task of software development starts here with data recording in the background (Mesaros et al., 2017). Once the software is developed, the implementation stage leads to a pilot study of the product to see if it works properly (Kupiainen, Mäntylä, \& Itkonen, 2015). The test stage evaluates the software for errors and bugs in documents and fixing them (Chopra, 2018; Hua et al., 2018). Once the software passes all the steps without any problems, it conducts a maintenance process in which it is maintained and upgraded from time to time to adapt to changes and release the software to the customer (Martin \& Finkelstein, 1989).

The Students and teachers from Universitas Pendidikan Indonesia in Bandung City participated in this study. The sample of this study is based on the data source and is divided into two parts. In the first part, there are 6 software engineer were participated in a responsive and functionality test of the system where 4 software engineer participated in responsive test and rest of the 2 software engineer participated in functionality test of the system. There were given the link of the system and a questionnaire form which was sent via Gmail. In a free structured interview, there were two students from the first semester of Mechanical Engineering Education Department, two teachers also from the same department participated in this study. The head of the SPOT e-learning system of UPI also participated in an interview. Quantitative research requires at least 20 (twenty) respondents to achieve substantial statistical value (Wimmer \& Dominick, 2013). In the second part, this study collects data from 25 respondents' bachelor students who had taken Applied Physics (Fisika Teknik) in their first semester, the students are from the Department of Mechanical Engineering Education at Universitas Pendidikan Indonesia, Bandung City. The URL of the system has been sent to the students and there were asked to use the system after they used the system, 
there were asked to fulfil an online questionnaire which was developed by Google forms and sent to them via Whatsapp group.

\section{Results and Discussion}

An OpenCourseWare system has been successfully developed using web technologies. OpenCourseWare e-learning information has been developed that is hosted online and can be accessed via a personal computer, laptop and other small devices with the Internet connection or can be used offline in localhost. The development has been done by analysing requirements, designing database and user interface, implementing design into a real product, and then performing system functionality, usability, and responsive testing to see the quality of the system. The test result of OpenCourseWare e-learning information system from functionality, usability and responsive or capability aspect indicates a quality information system which can be used by the Higher Education Institute to maintain online course materials and effective communication between teachers and students. The test result of functionality and responsive both aspect is 1 which indicates "Good" by ISO 9126 standard. The usability test results show that the value of alpha Cronbach, 0.909 is an "Excellent" category. The four aspects of the usability test the value of usefulness is $85 \%$, the value of the ease of use is $83 \%$, the value of the easement of learning is $52 \%$ and the value of satisfaction is $77 \%$. The e-learning information system uses responsive design and all the content of the system is responsive to small device beside a large device. So a student can access the system from a mobile phone device besides a large screen device. The e-learning information system has two interfaces which are student interface and administrator interface. Administrator Interface designed for administrator and teacher but the student interface only for the student where students can get access by their NIM and password. Using this system student and teacher communicate with each other, they are able to create a chat topic and then can start the chat. Chat can be identified by topic name. The system is used photo of teacher and students so it is easy for an identified teacher or student by their photo beside their name. The e-learning information system is a Single Page Application which really gives its user a better experience of browsing. The system store video to YouTube so that the system does not require a lot of storage, which reduces the hosting cost and besides the user access the videos from the system are able to access them on YouTube. Search Engine helps the user to find a course easily.

It is sugges that further research should be more in-depth and comprehensive, more specifically the developing course materials for this system. Students can get extra knowledge of modern web technologies and they will get used to some new English vocabularies by using this system. A complete user guide needs to develop and teachers and students need to be trained before they use this system. 


\section{Conclusion and Recommendation}

E-learning information system commonly uses bootstrap3; however, this study recommends using the latest version of the bootstrap so that the user interface would be more interactive. Form layout of this system is two columns. Creating a course on this system is one by one, meaning that the user can create one course at a time, which poses no problem. What becomes a problem is uploading course materials or videos. The researcher recommends using batch creating facilities for the user which means a user can upload or create more than one item at a time. Researcher suggests future developer to use the YouTube API on this system to integrate YouTube video so that users can upload lecture videos to YouTube using this system. This has a chance to save users' time and they will feel more comfortable. A chrome extension can be developed so that students and teacher can log in using their login details and they will able to chat using this chrome extension. The system users do not need to visit the original web portal. Using this chrome extension students also able to see if there are any chat notifications. This study only performs functionality, usability, and responsive test. More tests can be done in order to certify the quality of the e-learning system. The current e-learning system does not support any language, the text is used in this are fixed text. The language support tool can be helpful to use this in other languages for users who do not understand English properly.

\section{Acknowledgements}

I would like to take this opportunity to thank KNB scholarship authority for providing me such a great chance to study in Indonesia. I am very honored to be the recipient of this scholarship. Receiving this scholarship motivates me to maintain my CGPA and focus on my study. I look forward to being able to give back to the community once I begin my career. I would also like to extend my gratitude to Universitas Pendidikan Indonesia to help me achieve my goal.

\section{References}

Abrahamsson, P., Salo, O., Ronkainen, J., and Warsta, J. (2017). Agile software development methods: Review and analysis. arXiv Preprint arXiv:1709.08439.

Berchet, C., and Habchi, G. (2005). The implementation and deployment of an ERP system: An industrial case study. Computers in Industry, 56(6), 588-605.

Biggs, J. B. (2011). Teaching for quality learning at university: What the student does. McGraw-Hill Education (UK).

Brisebois, M. A., Drummond, B., Mehta, A., Chene, M., and Flannigan, M. (2017). Method and system for customizing a mobile application using a web-based interface. U.S. Patent No. $9,836,446$. Washington, DC: U.S. Patent and Trademark Office.

Burbules, N. (2018). Watch IT: The risks and promises of information technologies for education. Routledge. 
Carson, S. (2009). The unwalled garden: growth of the OpenCourseWare Consortium, 2001-2008. Open Learning, 24(1), 23-29.

Chopra, R. (2018). Software Testing: A Self-Teaching Introduction. Stylus Publishing, LLC.

Frain, B. (2015). Responsive web design with HTML5 and CSS3. Packt Publishing Ltd.

Grant, R. M. (2016). Contemporary strategy analysis: Text and cases edition. John Wiley \& Sons.

Hakami, N. A. M. (2018). An Investigation of the Motivational Factors Influencing Learners' Intentions to Continue Using Arabic MOOCs. University of Southampton, University Library.

Hua, J., Zhang, M., Wang, K., and Khurshid, S. (2018). Towards practical program repair with ondemand candidate generation. Proceedings of the 40th International Conference on Software Engineering, 12-23.

Hussain, A., and Mkpojiogu, E. O. C. (2015). The effect of responsive web design on the user experience with laptop and smartphone devices. Jurnal Teknologi (Sciences \& Engineering), 77(4), 41-47.

Hylén, J. (2006). Open educational resources: Opportunities and challenges. Proceedings of Open Education, 4963.

Jadhav, M. A., Sawant, B. R., and Deshmukh, A. (2015). Single page application using angularjs. International Journal of Computer Science and Information Technologies, 6(3), 2876-2879.

Jones, E., and Brown, S. (2007). Internationalising higher education. Routledge.

Kumar, V., and Jenamani, M. (2017). Context preserving navigation redesign under Markovian assumption for responsive websites. Electronic Commerce Research and Applications, 21, 65-78.

Kupiainen, E., Mäntylä, M. V., and Itkonen, J. (2015). Using metrics in Agile and Lean Software Development-A systematic literature review of industrial studies. Information and Software Technology, 62, 143-163.

Martin, J., and Finkelstein, C. (1989). Information engineering. Prentice Hall Englewood Cliffs, NJ.

McCanne, S., Demmer, M. J., Watson, D. J., and Wu, D. T.-S. (2016). Optimizing communications using client-side reconstruction scripting. Washington, DC: U.S. Patent and Trademark Office.

Mesaros, A., Heittola, T., Diment, A., Elizalde, B., Shah, A., Vincent, E., ... and Virtanen, T. (2017). DCASE 2017 challenge setup: Tasks, datasets and baseline system. DCASE 2017Workshop on Detection and Classification of Acoustic Scenes and Events.

Paulson, L. D. (2005). Building rich web applications with Ajax. Computer, 38(10), 14-17.

Rosenzweig, E. (2015). Successful user experience: Strategies and roadmaps. Morgan Kaufmann.

Siapera, E. (2017). Understanding new media. Sage.

Soma, K., Termeer, C. J. A. M., and Opdam, P. (2016). Informational governance-A systematic literature review of governance for sustainability in the Information Age. Environmental Science \& Policy, 56, 89-99. 
Souders, S. (2008). High-performance web sites. Communications of the ACM, 51(12), 36-41.

Straker, L., Harris, C., Joosten, J., and Howie, E. K. (2018). Mobile technology dominates school children's IT use in an advantaged school community and is associated with musculoskeletal and visual symptoms. Ergonomics, 61(5), 658-669.

Sun, J. C., Wu, Y., and Lee, W. (2017). The effect of the flipped classroom approach to OpenCourseWare instruction on students' self-regulation. British Journal of Educational Technology, 48(3), 713-729.

Tapia-Leon, M., Rivera, A. C., Chicaiza, J., and Luján-Mora, S. (2018). Application of ontologies in higher education: A systematic mapping study. Global Engineering Education Conference (EDUCON), 2018 IEEE, 1344-1353.

Turkle, S. (2017). Alone together: Why we expect more from technology and less from each other. Hachette UK.

Wimmer, R. D., and Dominick, J. R. (2013). Mass media research. Cengage learning.

Yanuschik, O. V, Pakhomova, E. G., and Batbold, K. (2015). E-learning as a Way to Improve the Quality of Educational for International Students. Procedia-Social and Behavioral Sciences, $215,147-155$.

Zaheer, H., Breyer, Y., Dumay, J., and Enjeti, M. (2019). Straight from the horse's mouth: Founders' perspectives on achieving "traction"in digital start-ups. Computers in Human Behavior, 95, 262-274. 